\title{
PERANCANGAN STRATEGIS SISTEM INFORMASI DI SMK DIPONEGORO 1 JAKARTA
}

\author{
Iwan Supriyantoko ${ }^{1}$ \\ ${ }^{1}$ Fakultas Teknik, Universitas Negeri Jakarta \\ E-mail: iwansupriyantoko@gmail.com
}

\begin{abstract}
SMK Diponegoro 1 Jakarta is an educational institution at Al-Hidayah Foundation Jakarta, located in East Jakarta. As a long-standing educational institution, SMK Diponegoro 1 Jakarta is growing rapidly, however, it has not implemented Information System and Information Technology optimally in its business process and does not yet have a portfolio of Information System strategic planning. So it is deemed necessary in making a strategic information system, in order to provide superior in business competition. Strategic planning of information systems become one of the key in implementing information systems and information technology on business activities. Appropriate strategic planning can support the organization's business plan and development. The strategic planning form that will be discussed in this research uses Ward and Preppard methodology with PEST, Five Force Model, SWOT, Value Chain, and Mc Farlan Strategic Gird analysis methods. The result of this analysis defines the company's strategic information system planning in the form of business strategy of information system, information system management strategy and information technology, information system strategy, information system recommendation, upcoming application and implementation plan
\end{abstract}

Keywords : Strategic Planning of Information Systems, Ward and Peppard

\begin{abstract}
ABSTRAK
SMK Diponegoro 1 Jakarta merupakan lembaga pendidikan pada Yayasan Al-Hidayah Jakarta yang berada di Jakarta Timur. Sebagai lembaga pendidikan yang tergolong lama, SMK Diponegoro 1 Jakarta berkembang dengan pesat, namum belum menerapkan Sistem Informasi dan Teknologi Informasi secara optimal dalam proses bisnisnya dan belum memiliki sebuah portofolio perencanaan strategis Sistem Informasi. Sehingga dipandang perlu dalam membuat sebuah sistem informasi strategis, guna memberikan unggulan dalam persaingan bisnisnya. Perencanaan strategis sistem informasi menjadi salah satu kunci dalam menerapkan sistem informasi dan teknologi informasi pada kegiatan bisnis. Perencanaan strategis yang tepat dapat mendukung rencana dan pengembangan bisnis organisasi. Bentuk perencanaan strategis yang akan dibahas dalam penelitian ini menggunakan metodologi Ward and preppard dengan alat bantu metode analisis PEST, Five Force Model, SWOT, Value Chain, dan metode analisis Mc Farlan Strategic Gird. Hasil anadari analisis ini mendefinisikan perusahaan perencanaan strategis sistem informasi berupa strategi bisnis sistem informasi, strategi manajemen sistem informasi dan teknologi informasi, strategi sistem informasi, rekomendasi sistem informasi, aplikasi yang akan datang dan rencana implementasi.
\end{abstract}

Kata Kunci - Perencanaan Strategis Sistem Informasi, Ward and Peppard

\section{PENDAHULUAN}

Perkembangan teknologi yang sangat cepat sekarang ini khususnya teknologi informasi dan system informasi, menyebabkan perubahan-perubahan peran yang penting menyebabkan perubahanperubahan peran yang penting dalam proses bisnis sebuah organisasi serta memberikan efek yang efisien dan efektifitas kinerja organisasi. Karena perannya yang strategis, teknologi informasi juga mampu membuat sebuah organisasi dapat memperoleh keunggulan kompetitif sebagai senjata kompetitif yang digunakan untuk berkompetisi. Untuk itu diperlukan suatu perencanaan strategis system informasi dimana penerapan system informasi pada sebuah lingkungan pendidikan dapat dipastikan sejalan dan mendukung strategi visi, misi, dan tujuan sekolah.

Untuk meningkatkan mutu pendidikan, pemerintah telah mengeluarkan Undang-Undang Nomor 20 Tahun 2003, 
mengenai Sistem Pendidikan Nasional pasal 32 ayat 2 yang menyebutkan bahwa Standar Nasional Pendidikan dgunakan sebagai acuan pengembangan kurikulum, tenaga kependidikan, sarana dan prasarana, pengelolaan, dan pembiayaan. Hal ini dilakukan pemerintah agar menghasilkan lulusan yang berkualitas.

SMK Diponegoro 1 Jakarta Timur merupakan salah satu lembaga pendidikan menengah kejuruan yang mempunyai beberapa jurusan meliputi Teknik Komputer dan Jaringan, Multimedia, Akuntansi dan Administrasi Perkantoran yang beralamatkan di jalan Sunan Giri No 5 Rawamangun Jakarta Timur. Kondisi system informasi di SMK Diponegoro 1 Jakarta Timur saat ini masih belum terintegrasi dengan baik, diantaranya system tersebut adalah system informasi akademik, system informasi kerjasama, sarana dan prasarana, system organisasi, system informasi keuangan dan system informasi PPDB. Beberapa system informasi yang akan dikembangkan belum mempunyai acuan, arahan atau pedoman yang jelas, sehingga dapat mengakibatkan kurangnya kinerja institusi SMK Diponegoro 1 Jakarta Timur secara menyeluruh. Karenanya diperlukan perencanaan strategis system informasi yang tepat sesuai dengan metode yang ada. Tujuan dari penelitian ini yaitu membuat sebuah usulan perencanaan strategis system informasi guna memberikan keunggulan atau nilai tambah dari layanan yang tersedia di dalam proses bisnis SMK Diponegoro 1 Jakarta Timur.

Adapun batasan pada penelitian ini adalah studi kasus dilakukan pada perusahaan jasa yang berupa sebuah lembaga pendidikan swasta SMK Diponegoro 1 Jakarta Timur. Hasil akhir penelitian ini berupa portofolio perencanaan strategis system informasi. Metodologi yang dgunakan adalah metodologi perencanaan strategis versi Ward and Peppard. Alat bantu yang digunakan adalah metode analisis PEST, Five Forces Model, SWOT, metode analisis Value Chain dan metode analisis McFarlan Strategic Grid.

\section{METODE}

Dalam membuat suatu perencanaan strategi yang baik diperlukan langkah- langkah dalam melakukan penelitian serta metode yang akan digunakan. Gambar merupakan langkah-langkah penelitian yang akan dilakukan berupa model strategis yang dibuat menggunakan metode Ward and Peppard.

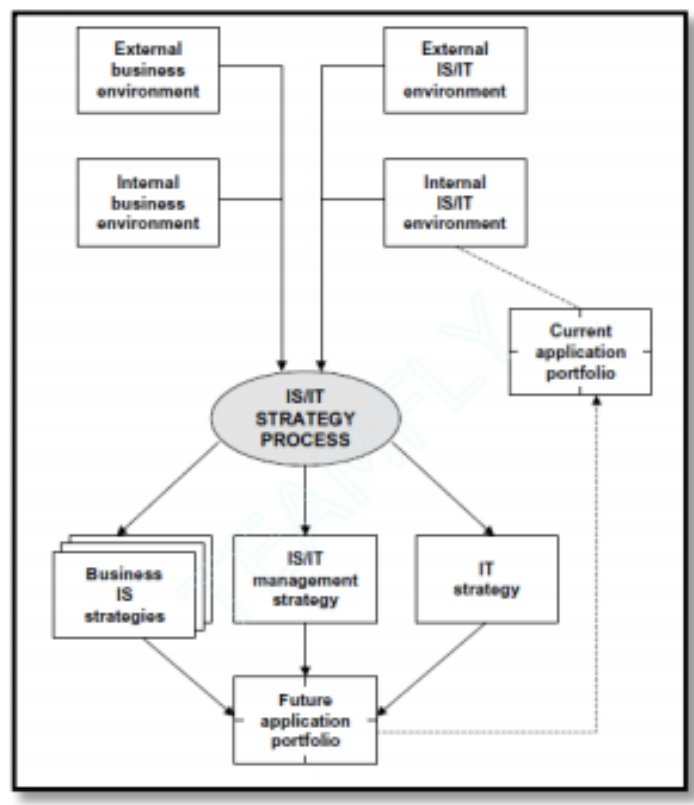

Gambar 4. Metodologi Strategi SI/TI menurut Ward dan Peppard

\section{HASIL DAN PEMBAHASAN} Pengertian Perencanaan Strategi

Perencanaan merupakan sebuah analisis yang menyeluruh dan sistematis dalam mengembangkan sebuah rencana kegiatan (Ward and Peppard, 2002).

Strategi adalah tujuan jangka panjang dari suatu perusahaan, serta pendayagunaan dan alokasi semua sumber daya yang penting untuk mencapai tujuan tersebut (F. Rangkuti, 2006). Pemahaman tentang konsep strategi yang baik sangat menentukan suksesnya strategi yang disusun meliputi :

a. Distinctive competence: tindakan yang dilakukan oleh perusahaan agar dapat melakukan kegiatan lebih baik dibandingkan dengan pesaingnya

b. Competitive advantage: kegiatan spesifik yang dikembangkan oleh perusahaan agar lebih unggul dibandingkan dengan pesaingnya

Perencanaan Strategis (Strategic Planning) menurut Kerzner (2001) adalah sebuah alat manajemen yang digunakan untuk mengelola kondisi saat ini untuk melakukan proyeksi kondisi pada masa depan, sehingga rencana strategis adalah 
sebuah petunjuk yang dapat digunakan organisasi dari kondisi saat ini untuk mereka bekerja menuju 5 sampai 10 tahun ke depan.

\section{Perencanaan Strategis Sistem Informasi}

Perencanaan strategi sistem informasi merupakan suatu proses analisis yang menyeluruh dan sistematis dalam merumuskan tujuan dan sasaran perusahaan serta menentukan strategi yang memanfaatkan keunggulan sistem informasi dan dukungan teknologi informasi dalam menunjang strategi bisnis dan memberikan perusahaan suatu keunggulan jangka panjang untuk menghadapi persaingan dengan perusahaan lainnya.

Beberapa teori ini merujuk pada beberapa jurnal Sensuse (2008) yang telah membahas pada penelitian yang sama yaitu tentang: Keselarasan SI/TI dalam strategi bisnis, Model Perencanaan Strategi SI, Value chain analysis, dan Five Force Model.

\section{Analisis SWOT}

Analisis SWOT adalah metode manajemen strategis yang digunakan untuk mengevaluasi kekuatan, kelemahan, peluang, dan ancaman (dalam Rohman, 2016).

1. Strength (kekuatan) merupakan sumber daya atau kapabilitas yang dikendalikan oleh atau tersedia bagi suatu organisasi yang membuat organisasi relatif lebih unggul dibandingkan pesaingnya dalam memenuhi kebutuhan pelanggan yang dilayaninya

2. Weakness (kelemahan) merupakan keterbatasan atau kekurangan dalam satu atau lebih sumber daya atau kapabilitas suatu perusahaan relatif terhadap pesaingnya, yang menjadi hambatan dalam memenuhi kebutuhan pelanggan secara efektif.

3. Opportunity (peluang) merupakan situasi atau tren yang menguntungkan dalam lingkungan suatu organisasi. Munculnya segmen pasar baru dan membaiknya hubungan antara pembeli dan pemasok adalah contoh faktor yang dapat menjadi peluang bagi organisasi

4. Threat (ancaman) merupakan situasi atau tren yang tidak menguntungkan dalam lingkungan suatu organisasi. Munculnya pesaing baru adalah contoh faktor yang dapat menjadi ancaman bagi organisasi.

Setelah mengidentifikasi faktor-faktor SWOT (Strongth, Weakness, Opportunities, Threathment), analisis selanjutnya menyusun Matrik SWOT. Matriks SWOT adalah alat untuk menyusun faktor-faktor strategis organisasi yang dapat menggambarkan secara jelas bagaimana peluang dan ancaman eksternal yang dihadapi organisasi dapat disesuaikan dengan kekuatan dan kelemahan yang dimilikinya.

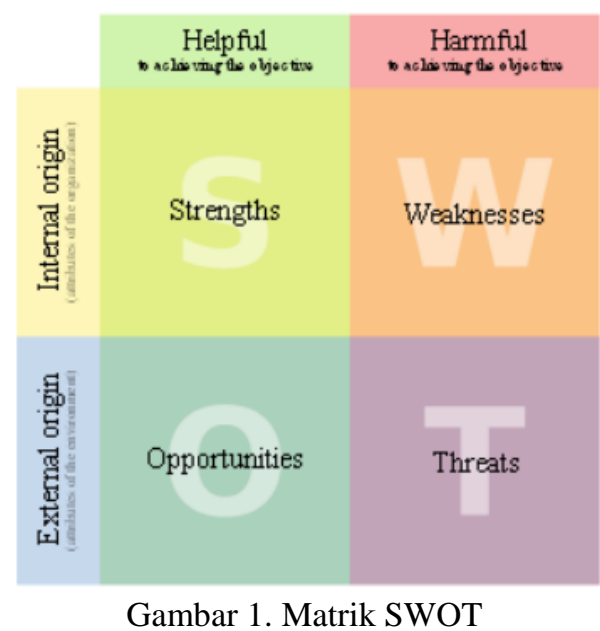

Matriks SWOT (Matriks ThreatsOpportunities Weakness-Strengths (TOWS)) merupakan alat pencocokan yang penting yang membantu manajer mengembangkan 4 (empat) tipe strategi :

1. Strategi SO, kombinasi antara Stength dengan Opportunity adalah bagaimana cara untuk mengambil keuntungan dari kekuatan yang ada.

2. Strategi WO, kombinasi antara Weakness dengan Opportunity adalah bagaimana mengatasi kelemahan dengan memanfaatkan peluang yang ada

3. Strategi ST, kombinasi antara Stength dengan Threat adalah bagaimana cara kekuatan menghadapi ancaman yang ada

4. Strategi WT, kombinasi antara Weakness dengan Threat adalah bagaimana kelemahan yang ada di internal tidak menambah menjadi ancaman

\section{PEST}

Menurut Ward dan Peppard (2002), PEST terdiri dari empat bagian, yaitu : 
1. Politik: meliputi peraturan pemerintah dan kebijakan perusahaan DU/DI

2. Ekonomi: semua faktor yang mempengaruhi daya beli masyarakat

3. Sosial: meliputi kesadaran masyarakat terhadap pentingnya pendidikan

4. Teknologi: meliputi tren teknologi yang sedang berkembang

\section{Value Chain}

Menurut Ward dan Peppard (2002), analisis value chain adalah kegiatan menganalisis kumpulan aktivitas yang dilakukan untuk merancang, memproduksi, memasarkan, mengantarkan, dan mendukung produk atau jasa. Pendekatan value chain dibedakan menjadi dua tipe aktivitas bisnis, yaitu aktivitas utama (primary activities) dan aktivitas pendukung (support activities).

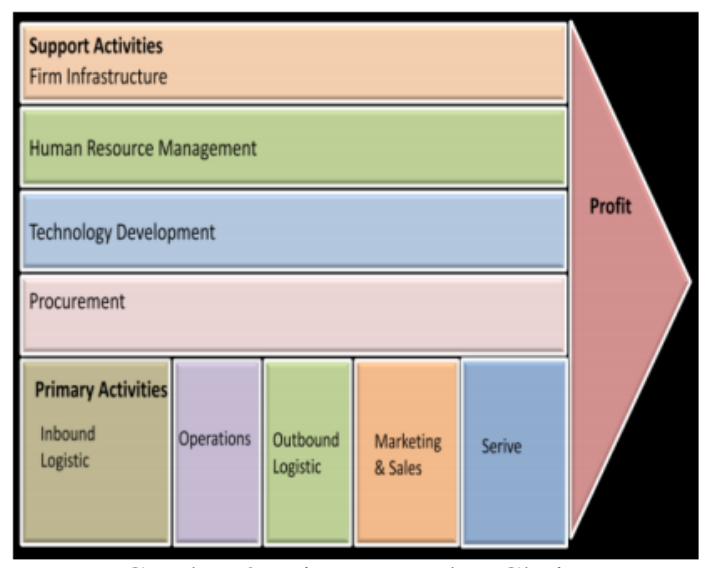

Gambar 2. Diagram Value Chain
Analisis Mc. Farlan

Menurut Ward dan Peppard (2002), analisis mcFarlan strategic grid digunakan untuk memetakan aplikasi SI berdasarkan konstribusinya terhadap organisasi. Pemetaan dilakukan pada empat kuadran (strategic, high potential, key operation, and support).

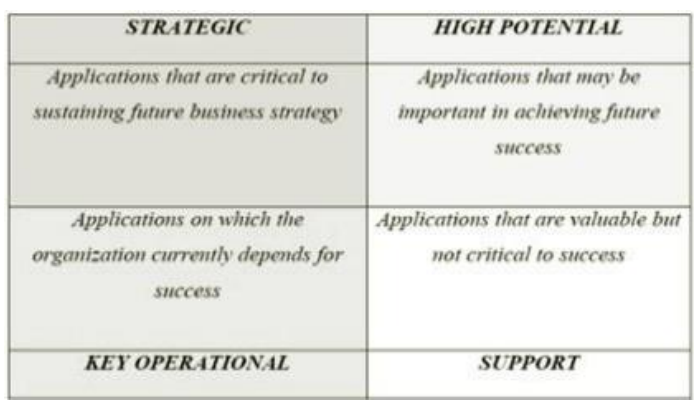

Gambar 3. McFarlan Strategic Grid

\section{Faktor Lingkungan Bisnis Eksternal dan Lingkungan Eksternal SI dan TI SMK Diponegoro 1 Jakarta Timur}

1. Analisis PEST

Faktor-faktor eksternal yang berpengaruh pada saat ini bagi SMK Diponegoro 1 Jakarta Timur menggunakan analisis PEST meliputi aspek sebagai berikut:

Tabel 1. Analisis Lingkungan Bisnis Eksternal menggunakan PEST

\begin{tabular}{|l|l|l|}
\hline Kategori & Peluang & Ancaman \\
\hline Politik & $\begin{array}{l}\text { Stabilitas politik dan } \\
\text { keamanan yang kondusif } \\
\text { sehingga memungkinkan } \\
\text { SMK Diponegoro 1 Jakarta } \\
\text { Timur menjalankan proses } \\
\text { bisnisnya dengan baik }\end{array}$ & $\begin{array}{l}\text { Peraturan pemerintah } \\
\text { melalui Badan Akreditasi } \\
\text { Nasional (BAN S/M) yang } \\
\text { mengatur status akreditasi } \\
\text { suatu sekolah seperti untuk } \\
\text { menentukan kelayakan } \\
\text { program }\end{array}$ \\
\hline Ekonomi & $\begin{array}{l}\text { Bantuan pemerintah pusat } \\
\text { dan daerah melalui dinas } \\
\text { pendidikan }\end{array}$ & $\begin{array}{l}\text { Mayoritas pendapatan } \\
\text { masyarakat yang sedang }\end{array}$ \\
& $\begin{array}{l}\text { Kenaikan harga dan } \\
\text { inflasi }\end{array}$ \\
\hline Sosial & $\begin{array}{l}\text { Kesadaran masyarakat mulai meningkat } \\
\text { tentang pendidikan }\end{array}$ & $\begin{array}{l}\text { Sekolah Negeri yang } \\
\text { mengembangkan program } \\
\text { sejenis }\end{array}$ \\
& $\begin{array}{l}\text { Dukungan masyarakat } \\
\text { DKI Jakarta khususnya } \\
\text { masyarakat Jakarta Timur }\end{array}$ & \\
\hline
\end{tabular}




\begin{tabular}{|c|c|c|}
\hline Kategori & Peluang & Ancaman \\
\hline Teknologi & $\begin{array}{l}\text { - Perkembangan teknologi } \\
\text { informasi yang cepat } \\
\text { - Banyaknya sumber yang } \\
\text { open source yang bisa } \\
\text { digunakan untuk } \\
\text { membangun aplikasi yang } \\
\text { berbasis desktop, web } \\
\text { maupun mobile }\end{array}$ & 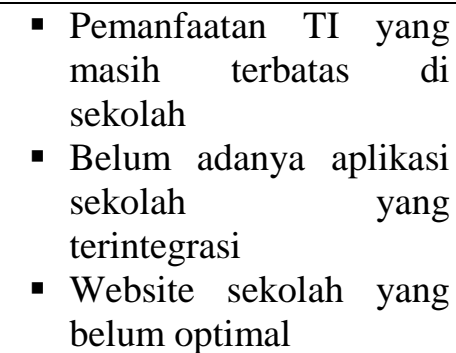 \\
\hline
\end{tabular}

2. Analisis Five Forces Model

Analisis Five Forces Model digunakan untuk menentukan posisi SMK Diponegoro 1 Jakarta Timur terhadap lingkungan eksternal yang mempengaruhi jalannya proses bisnis pada SMK Diponegoro 1 Jakarta Timur dan mengidentifikasi ancaman-ancaman atau tekanan-tekanan kompetisi (Competitive Forces Model) dari kompetitor (lingkungan bisnis eksternal). Berikut ini adalah hasil analisis Five Forces Model:

Tabel 2. Analisis Lingkungan Bisnis Eksternal menggunakan Five Force

\begin{tabular}{|c|c|c|}
\hline Forces & Peluang & Ancaman \\
\hline Pendatang Baru & $\begin{array}{l}\text { - Masih } \\
\text { SMA/SMK sedikit } \\
\text { program sejenis di } \\
\text { Jakarta Timur } \\
\text { - SMK Diponegoro 1 } \\
\text { Jakarta Timur memiliki } \\
\text { hubungan masyarakat } \\
\text { sekitar dan lembaga- } \\
\text { lembaga pemerintah } \\
\text { maupun non pemerintah }\end{array}$ & $\begin{array}{l}\text { Peraturan pemerintah daerah } \\
\text { tentang pendirian sekolah } \\
\text { untuk kemajuan pendidikan } \\
\text { di Jakarta sehingga } \\
\text { memudahkan seseorang atau } \\
\text { kelompok untuk membentuk } \\
\text { lembaga pendidikan }\end{array}$ \\
\hline Pelanggan & Biaya iuran yang terjangkau & $\begin{array}{ll}\text { Keinginan } & \text { pelanggan } \\
\text { dengan kualitas } & \text { pendidikan } \\
\text { yang tinggi } & \end{array}$ \\
\hline Pesaing & $\begin{array}{l}\text { SMK Diponegoro 1 Jakarta } \\
\text { Timur memiliki } \\
\text { proses bisnis yaitu Kalbis } \\
\text { Institut }\end{array}$ & $\begin{array}{l}\text { Pesaing yang sudah lebih } \\
\text { dahulu berdri dan memiliki } \\
\text { jaringan yang luas sehingga } \\
\text { proses bisnis pesaing lebih } \\
\text { kuat }\end{array}$ \\
\hline Produk Subtitusi & $\begin{array}{l}\text { Lebih banyak memiliki } \\
\text { instrument-instrumen yang } \\
\text { menunjan pendidikan } \\
\text { seperti infrastruktur dan } \\
\text { materi pendidikan yang } \\
\text { diberikan }\end{array}$ & $\begin{array}{l}\text { Tumbuh pesatnya jenjang } \\
\text { pendidikan } 1 \text { tahun dan } \\
\text { lembaga kursus sehingga } \\
\text { memungkinkan } \\
\text { menggantikan posisi } \\
\text { pendidikan formal dalam hal } \\
\text { lapangan pekerjaan di dunia } \\
\text { kerja }\end{array}$ \\
\hline Pemasok & $\begin{array}{l}\text { Memiliki hubungan baik } \\
\text { dan kerja sama dengan } \\
\text { beberapa sekolah menengah } \\
\text { pertama (SMP) }\end{array}$ & $\begin{array}{l}\text { Pentingnya Akreditas } \\
\text { sebagai jaminan mutu } \\
\text { pendidikan }\end{array}$ \\
\hline
\end{tabular}



Faktor lingkungan Bisnis Internal dan lingkungan Internal SI dan TI di SMK Diponegoro 1 Jakarta Timur

1. Analisis Value Chain

Analisis Value Chain bertujuan untuk mengidentifikasi dan mengelompokkan aktifitas-aktifitas yang terjadi di SMK Diponegoro 1 Jakarta Timur ke dalam dua bagian besar yaitu aktifitas utama dan aktifitas pendukung

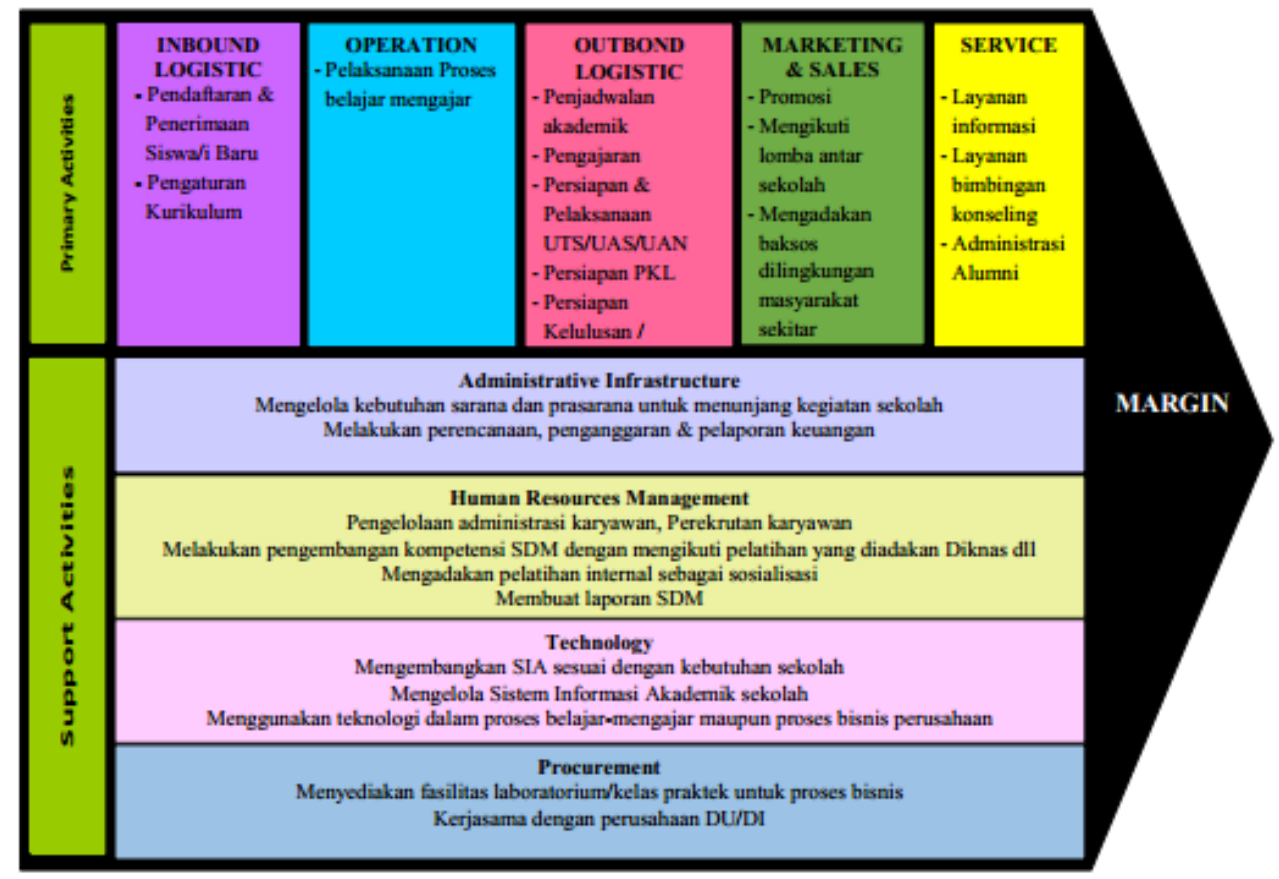

Gambar 5. Analisis Value Chain

\section{Analisis SWOT}

Digunakan untuk mengetahui kekuatan (Strength) dan kelemahan (Weakness) dari sumber daya yang dimiliki organisasi serta peluang (Opportunities) dan ancaman (Threat) pada lingkungan organisasi.

Tabel 3. Matriks Analisis SWOT SMK Diponegoro 1 Jakarta Timur

\begin{tabular}{|c|c|c|}
\hline Ext & 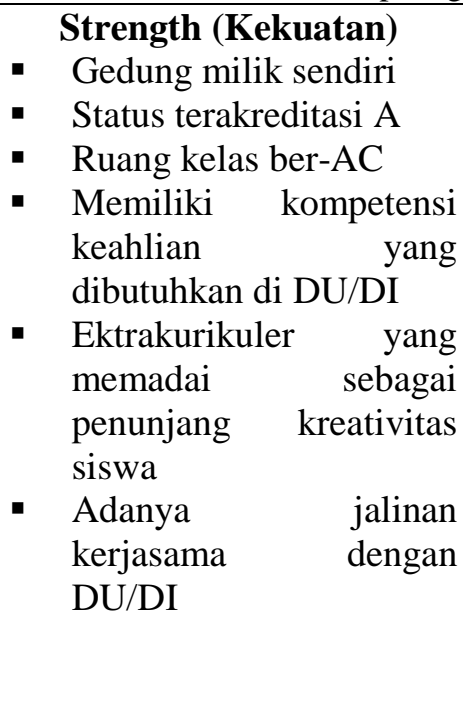 & 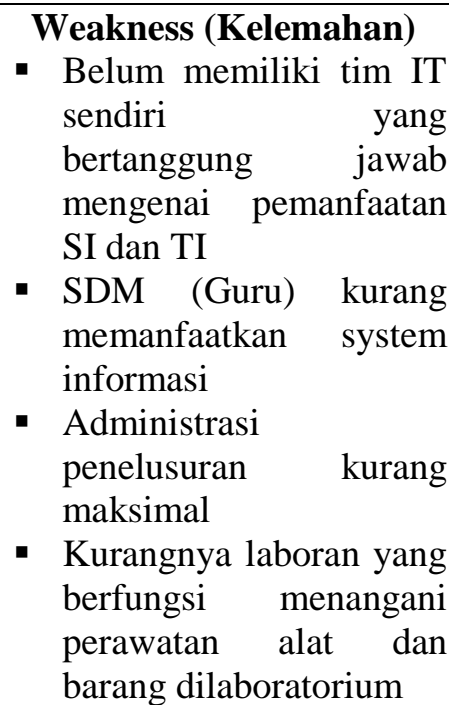 \\
\hline \begin{tabular}{lr}
\multicolumn{2}{c}{ Opportunity (Peluang) } \\
- Siswa & mudah \\
melanjutkan & ke \\
jenjang & yang
\end{tabular} & 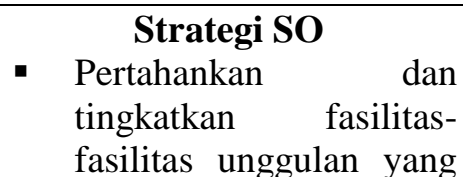 & 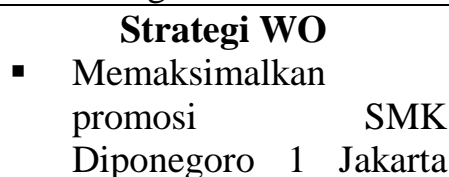 \\
\hline
\end{tabular}




\begin{tabular}{|c|c|c|}
\hline $\begin{array}{ll} & \text { berikutnya } \\
\text { - } & \text { Mendapatkan bantuan } \\
\text { dari pemerintah } \\
\text { melalui pemerintah } \\
\text { daerah (BOS) } \\
\text { - Lokasi strategis dan } \\
\text { mudah terjangkau } \\
\text { - Kompetensi keahlian } \\
\text { memenuhi kebutuhan } \\
\text { DU/DI } \\
\text { - Memiliki hubungan } \\
\text { baik dengan } \\
\text { pemerintah dan non } \\
\text { pemerintah } \\
\text { Memiliki hubungan } \\
\text { baik dengan } \\
\text { masyarakat }\end{array}$ & $\begin{array}{l}\text { dimiliki } r \text { SMK } \\
\text { Diponegoro 1 Jakarta } \\
\text { Timur } \\
\text { Jalin lebih jauh kerja } \\
\text { sama dengan mitra } \\
\text { kerja, agar lulusan SMK } \\
\text { Diponegoro 1 Jakarta } \\
\text { Timur mudah dalam } \\
\text { mendapatkan pekerjaan } \\
\text { Merawat atau } \\
\text { menambah fasilitas agar } \\
\text { proses kegiatan } \\
\text { pendidikan meningkat }\end{array}$ & $\begin{array}{l}\text { Timur lebih baik lagi } \\
\text { agar menjaring siswa } \\
\text { baru lebih banyak lagi } \\
\text { - Meningkatkan sarana } \\
\text { dan prasarana } \\
\text { - Menambah ruang } \\
\text { praktek/laboratorium } \\
\text { - Memberikan pelatihan } \\
\text { kepada SDM yang } \\
\text { sesuai dengan } \\
\text { kebutuhan }\end{array}$ \\
\hline $\begin{array}{l}\text { Threath (Ancaman) } \\
\text { - Adanya SMK lain } \\
\text { yang membuka } \\
\text { jurusan yang sama } \\
\text { - Kebijakan yang ketat } \\
\text { tentang kurikulum dari } \\
\text { pemerintah mengenai } \\
\text { standar pendidikan } \\
\text { - Dampak globalisasi di } \\
\text { sektor pendidikan } \\
\text { yang menuntut } \\
\text { kekuatan kompetensi } \\
\text { yang baik di taraf } \\
\text { nasional dan } \\
\text { internasional lulusan } \\
\text { - Permintaan dari } \\
\text { kualitas tinggi dar } \\
\text { pemerintah dan } \\
\text { DU/DI PI Perkembangan } \\
\text { teknolog yang cepat }\end{array}$ & $\begin{array}{l}\text { Strategi ST } \\
\text { - Meningkatkan strategi } \\
\text { dengan memanfaatkan } \\
\text { kekuatan untuk } \\
\text { mengatasi ancaman agar } \\
\text { SMK Diponegoro 1 } \\
\text { Jakarta Timur tidak } \\
\text { kalah dalam persaingan } \\
\text { bisnis } \\
\text { Meningkatkan } \\
\text { kompetensi guru dan } \\
\text { karyawan } \\
\text { meningkatkan } \\
\text { kesejahteraan guru dan } \\
\text { karyawan } \\
\text { meningkatkan kerjasama } \\
\text { dari berbagai pihak } \\
\text { Meningkatkan kualitas } \\
\text { lulusan }\end{array}$ & 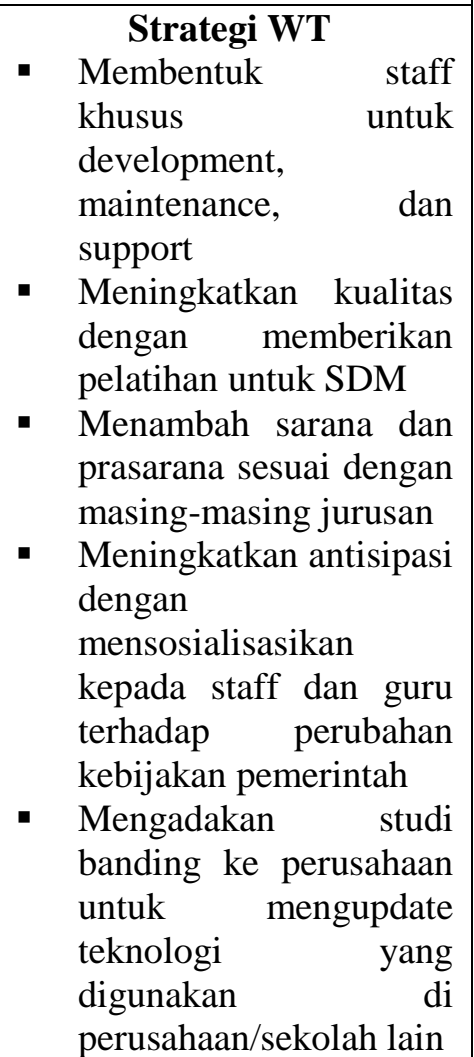 \\
\hline
\end{tabular}

3. Analisis McFarlan Strategic Grid Analisis McFarlan Strategic Grid digunakan untuk mengetahui kondisi SI dan TI yang ada di organisasi saat ini. Berikut Analisis McFarlan Strategic Grid di SMK Diponegoro 1 Jakarta Timur :
Tabel 4. Current Application Portofolio

\begin{tabular}{|l|l|}
\hline \multicolumn{1}{|c|}{ Strategic } & \multicolumn{1}{c|}{ Hight Potential } \\
\hline $\begin{array}{l}\text { Belum } \\
\text { menggunakan } \\
\text { system informasi }\end{array}$ & $\begin{array}{l}\text { Belum } \\
\text { menggunakan } \\
\text { system informasi }\end{array}$ \\
\hline $\begin{array}{l}\text { Belum } \\
\text { menggunakan } \\
\text { system informasi }\end{array}$ & $\begin{array}{l}\text { Internet } \\
\text { Website } \\
\text { sekolah }\end{array}$ \\
\hline Key Operational & \multicolumn{2}{c|}{ Support } \\
\hline
\end{tabular}




\section{Pemetaan Strategi Bisnis Organisasi dan Kebutuhan Infomasi}

Pemetaan strategi bisinis dilakukan untuk mengetahui kebutuhan bisnis dan informasi di organisasi yang berdasarkan hasil analisis lingkungan bisinis organisasi. Tujuanya adalah sebagai pertimbangan untuk menetapkan usulan perencanaan strategis yang akan datang. Dari hasil analisis pemetaan strategi bisnis dan kebutuhan informasi yang di tunjukan pada table 4 dapat diketahui bahwa strategi bisnis SMK Diponegoro 1 Jakarta Timur yaitu meningkatkan mutu pendidikan dan SDM serta meningkatkan sarana prasarana dan pelayanan, yang disusun berdasarkan hasil analisis lingkungan bisnis pada SMK Diponegoro 1 Jakarta Timur, yang kemudian dari hasil analisis tersebut dapat diketahui kebutuhan informasi organisasi. Kebutuhan informasi tersebut berupa Data Akademik, Data Guru, Data karyawan, Data Keuangan, Data Siswa, Data alumni, Data Absensi guru atau karyawan dan Data Perpustakaan, Data Sarana prasarana, Data Aset organisasi, Data TI, serta Data Mitra Kerja.

1. Perencanaan Strategis Yang Diusulkan Perencanaan strategis yang diusulkan disusun berdasarkan hasil pemetaan strategi bisnis dan kebutuhan informasi organisasi. Penentuan perecanaan strategi tersebut diawali dengan penentuan strategi bisnis sistem informasi, kemudian penentuan strategi manajemen SI/TI, dan strategi SI dari SMK Diponegoro 1 Jakarta Timur.

2. Portofolio Aplikasi Yang Akan Datang Berdasarkan hasil dari strategi bisnis SI, manajemen strategi SI/TI dan Strategi SI guna menunjang sebuah Sistem Informasi Strategis pada SMK Diponegoro 1 Jakarta Timur, maka dapat disusun Future Application Portfolio dengan menggunakan McFarlan's Strategic Grid sebagai berikut :

Tabel 5. Future Application Portfolio

\begin{tabular}{|ll|ll|}
\hline \multicolumn{2}{|c|}{ Strategic } & \multicolumn{2}{|c|}{ Hight Potential } \\
\hline 1) & SI Akademik & 1) & SI PPDB \\
2) & SI Alumni dan & 2) & SI \\
& Tracer & & kepegawaian \\
3) & SI Kerjasama & 3) & SI Keuangan \\
\hline
\end{tabular}

\begin{tabular}{|ll|ll|}
\hline 4) & SI monitoring & & \\
& SI/TI & & \\
5) & Website & & \\
& Sekolah & & \\
\hline 1) & SI EPSBED & 1) & Internet \\
2) & SI Presensi & 2) & Aplikasi \\
& Karyawan & & Perkantoran \\
3) & SI PKL & 3) & SI Beasiswa \\
4) & SI Perpustakaan & & \\
5) & SI Inventaris & & \\
6) & SI Penggajian & & \\
\hline \multicolumn{2}{|l|}{ Key Operational } & & Support \\
\hline
\end{tabular}

\section{KESIMPULAN}

Berdasarkan hasil analisa yang dilakukan pada analisis lingkungan bisnis baik internal maupun eksternal organisasi maka dapat ditarik kesimpulan bahwa SMK Diponegoro 1 Jakarta memerlukan rencana strategis sistem informasi. Berdasarkan strategi bisnis SI, diperlukan visi misi SI/TI yang dapat selaras dengan visi, misi, serta tujuan dari SMK Diponegoro 1 Jakarta Timur. Berdasarkan strategi manajemen SI/TI, diperlukan restrukturisasi organisasi (penambahan tim atau divisi baru yang nantinya akan bertanggung jawab mengenai SI/TI organisasi), Penambahan staff, pengembangan kompentensi SDM SI/TI dan pembenahan di sisi Teknologi Informasi organisasi sehingga kegiatan bisnis dan layanan SI/TI di SMK Diponegoro 1 Jakarta Timur dapat terlaksana dengan baik. Berdasarkan strategi SI, dibutuhkan sebanyak empat belas (14) sistem informasi yang sudah dipetakan ke dalam McFarlan Strategic Grid yang kemudian untuk menunjang sebuah Sistem Informasi Strategis dalam bentuk Future Application Portfolio pada SMK Diponegoro 1 Jakarta Timur.

\section{DAFTAR PUSTAKA}

[1] Kerzner, Harold. Strategic Planning for Project Manajement: A Project Manajement Maturity Model. 7th Edition. John Willey \& Sons. 2001.

[2] Rangkuti,F. Analisis SWOT Teknik Membedah Kasus Bisnis. Gramedia Pustaka Utama. 2006.

[3] Sensuse, Dana Indra dan Hendri S. Perencanaan Strategi Sistem Dan Teknologi Informasi Pada St. Ignatius Education Center Palembang. Jurnal 
Ilmiah STMIK GI MDP. 2008. Vol.4 (3), pp.10-11

[4] Saifu Rohman, Wing Wahyu Winarno, M. Rudyanto Arief. Perencanaan Strategis Sistem Informasi (Studi Kasus: SMK Takhassus Al-Quran Wonosobo. 2016. Jurnal PPKM II 136-147

[5] J Ward, J Peppard. Strategic Planning for Information System. Third Edition. John Willey \& Sons. 2002. 